\title{
On Noise Assessment for Blended Wing Body Aircraft
}

\author{
Yueping Guo* \\ Boeing Research \& Technology, Huntington Beach, CA 92647 \\ Casey L. Burley ${ }^{\dagger}$ and Russell H. Thomas ${ }^{\ddagger}$ \\ NASA Langley Research Center, Hampton, VA 23681
}

\begin{abstract}
A system noise study is presented for the blended-wing-body (BWB) aircraft configured with advanced technologies that are projected to be available in the 2025 timeframe of the NASA N+2 definition. This system noise assessment shows that the noise levels of the baseline configuration, measured by the cumulative Effective Perceived Noise Level (EPNL), have a large margin of $34 \mathrm{~dB}$ to the aircraft noise regulation of Stage 4 . This confirms the acoustic benefits of the BWB shielding of engine noise, as well as other projected noise reduction technologies, but the noise margins are less than previously published assessments and are short of meeting the NASA N+2 noise goal. In establishing the relevance of the acoustic assessment framework, the design of the BWB configuration, the technical approach of the noise analysis, the databases and prediction tools used in the assessment are first described and discussed. The predicted noise levels and the component decomposition are then analyzed to identify the ranking order of importance of various noise components, revealing the prominence of airframe noise, which holds up the levels at all three noise certification locations and renders engine noise reduction technologies less effective. When projected airframe component noise reduction is added to the HWB configuration, it is shown that the cumulative noise margin to Stage 4 can reach $41.6 \mathrm{~dB}$, nearly at the NASA goal. These results are compared with a previous NASA assessment with a different study framework. The approaches that yield projections of such low noise levels are discussed including aggressive assumptions on future technologies, assumptions on flight profile management, engine installation, and component noise reduction technologies. It is shown that reliable predictions of component noise also play an important role in the system noise assessment. The comparisons and discussions illustrate the importance of practical feasibilities and constraints in aircraft system noise studies, which include aerodynamic performance, propulsion efficiency, flight profile limitation and many other factors. For a future aircraft concept to achieve the NASA $N+2$ noise goal it will require a range of fully successful noise reduction technology developments.
\end{abstract}

\section{Nomenclature}

$\begin{array}{ll}\text { ANOPP } & =\text { Aircraft NOise Prediction Program (NASA) } \\ A O A & =\text { angle of attack } \\ A P & =\text { approach flight condition } \\ A V C & =\text { NASA ERA's Advanced Vehicle Concept task contract results } \\ B P F & =\text { blade passage frequency } \\ B P R & =\text { engine bypass ratio, mass flow of rotor/fan to mass flow of core } \\ B W B & =\text { Blended Wing Body, Boeing specific design } \\ \mathrm{C} & =\text { chord of wing or vertical or horizontal stabilizer } \\ C B & =\text { cutback flight condition } \\ C U M & =\text { cumulative noise, EPNdB, the summation of takeoff, cutback and approach conditions } \\ D & =\text { diameter of engine at fan nozzle exit plane }\end{array}$

\footnotetext{
* Technical Fellow, Acoustics Technology, 5301 Bolsa Ave, Huntington Beach, CA, AIAA Associate Fellow

${ }^{\dagger}$ Senior Research Engineer, Aeroacoustics Branch, MS 461, AIAA Senior Member

‡ Senior Research Engineer, Aeroacoustics Branch, MS 461, AIAA Senior Member
} 


$\begin{array}{ll}d B & =\text { decibel } \\ E R A & =\text { NASA's Environmentally Responsible Aviation Project } \\ E P N L & =\text { effective perceived noise level, decibels } \\ f & =\text { frequency }(\mathrm{Hz}) \\ H W B & =\text { Hybrid Wing Body, generic term } \\ L / D & =\text { lift-to-drag ratio } \\ L S A F & =\text { Low Speed Aeroacoustic Facility, Boeing } \\ M_{0} & =\text { Free stream Mach Number } \\ N+2 & =\text { NASA terminology for aircraft technology entering service in } 2025 \\ P A A & =\text { Propulsion Airframe Aeroacoustics } \\ P N L T & =\text { perceived noise level, tone corrected } \\ S F C & =\text { specific fuel consumption } \\ S P L & =\text { sound pressure level } \\ T O & =\text { takeoff flight condition } \\ U H B & =\text { ultra high bypass ratio engine }\end{array}$

\section{Introduction}

The blended-wing-body (BWB) aircraft has been studied for a long time as a potential candidate for future commercial aircraft due to desirable features such as noise reduction and fuel savings (e.g. Ref 1-3). Its low noise potential has attracted much attention in recent years with various assessed noise levels reported. For example, Refs 4 and 5 reported that a combination of advanced technologies within the 2025 timeframe could give the BWB aircraft a noise margin exceeding the NASA N+2 noise goal of $43 \mathrm{~dB}$ cumulative Effective Perceived Noise Level relative to the noise regulation of Stage 4 . A similar noise margin of $42 \mathrm{~dB}$ was assessed in Ref 6 . Furthermore, Ref 7 claimed a much higher margin of $74 \mathrm{~dB}$ for a flying wing configuration that uses imbedded engines and targeted to the same NASA N+2 goal and timeframe. The study of Refs 8-11 claimed that the margin could reach as high as 75 $\mathrm{dB}$ when considering a higher risk set of technologies and design approaches that might be available in a much later timeframe. If achieved, these are surprisingly low noise levels compared to what is achieved in today's aircraft. As a reference point, the latest generations of commercial aircraft in service, such as the Boeing 787 and the Airbus 380, have cumulative noise margins of about $15 \mathrm{~dB}$ to Stage 4 . In fact, the above mentioned studies approach the desired goal of a step change in aircraft noise reduction from varied perspectives and frameworks as well as use different technology assumptions and information to perform the studies. The focus of this paper will be two studies focused on the framework of the NASA N+2 goals and timeframe of aircraft in service in 2025. To achieve the noise margin of the NASA N+2 noise goal, aircraft noise levels would have to decrease by about $28 \mathrm{~dB}$ from current levels in the next 10 years. This is a very aggressive goal, because of the extremely difficult challenges that would have to be overcome to develop and mature to full success the technologies necessary in such a short timeframe.

In this paper, a system noise study will be presented, also using the projection of advanced technologies for the NASA N+2 goal and timeframe, but applying these technologies to a BWB design that is considered most likely to be viable, both technically and economically, as an alternative to conventional commercial aircraft. This assessment will confirm the acoustic benefits, with a cumulative noise margin of about $34 \mathrm{~dB}$ to Stage 4 , due to the combination of BWB noise shielding and the advanced technologies that are not ready now but are projected to mature and enter service in the next 10 to 15 years. While this is a significant margin to the aircraft noise regulations, both the current Stage 4 and the potentially more stringent Stage 5 expected in the near future, it is substantially smaller than previously published results and is short of meeting the NASA N+2 noise goal of $42 \mathrm{~dB}$ below Stage 4 . It is important to discern the sources of this difference, helping to set the baseline expectation of the noise levels of the BWB aircraft, which is the objective of the work presented here. In a final step, this study projects the airframe noise reduction technologies and levels that would be necessary to add to the baseline configuration in order for the BWB configuration to reach the NASA N+2 noise goal.

To establish the relevance of the acoustic analysis framework, the BWB aircraft configuration will first be described, which results from a systematic design study (Ref 3), employing the best practice in aircraft design with both practical feasibility and advanced technologies taken into account. The design follows the principles of commercial aircraft design to achieve the mission requirements, and the configuration meets the Federal Aviation Administration (FAA) FAR Part 25 regulations and other conventional requirements. Details of the design are documented in Ref 3 and the main aspects related to the acoustic analysis, including the projected advanced technologies, will be discussed in this paper. The importance of using such a realistic configuration in aircraft system noise assessment should be emphasized because achieving a noise goal is only one of multiple goals of an 
aircraft design. Instead, many other important factors such as propulsion efficiency and aerodynamic performance must be prioritized in the design process in order to meet various mission requirements. Obviously, the noise assessment would be trivial and irrelevant without the practical constraints in aircraft design, because without the practical constraints, a low noise goal might be achievable, by artificially and unrealistically lowering the flight speed and engine power, for example, which would allow the noise to be reduced to any arbitrarily low levels, according to the fundamental theory of aerodynamic sound (Ref 12) that predicts the noise as an increasing function of speed and engine power.

Due to the unconventional airframe design, the upper surface engine installation, and the unique operating conditions of the BWB aircraft, the noise assessment will consist of a hybrid method, making use of a combination of experimental data, empirical correlation, physics-based modeling and numerical simulation. This is essentially because aircraft noise assessment and prediction tools have largely been developed for conventional aircraft, and thus, cannot be directly applied to BWB configurations. The application will have to rely on component level predictions to accommodate the relevant features. Airframe noise is an example where the prediction tools will be updated and reassembled to account for features such as the lack of flaps, the large aircraft angle of attack, the effects of landing gear installation locations, and the use of trailing edge elevons. Furthermore, empirical data will be used where new component features are not modeled in existing tools, noise shielding by the BWB airframe being an example where the shielding effects will be extracted and extrapolated from model scale wind tunnel test data. The acoustic benefits of advanced noise reduction technologies will also be mainly based on experimental data and empirical correlations, mostly from model scale wind tunnel tests.

The acoustic analysis will lead to detailed noise component decomposition at all three noise certification conditions, namely, the approach, cutback and sideline conditions, which in turn result in the cumulative EPNL margin of $34 \mathrm{~dB}$ with reference to Stage 4. It will be shown, even for takeoff operations, that the joint effects of advanced engine design and BWB shielding make the noise from the engines no longer the dominant component, in contrast to the case for conventional aircraft currently in service. At cutback and sideline conditions, engine noise will be shown to be comparable to slat noise, and at approach conditions, the total aircraft noise is dominated by the components from the main landing gears and the slats. This is an interesting new ranking order of importance in aircraft noise components, drastically different from conventional aircraft whose total noise is dominated by engine noise. The new ranking order can serve as a guideline for the direction of technology development for further noise reduction, emphasizing the importance of the airframe noise components. For example, it has been shown that the BWB engine noise can be reduced by a series of technologies increments, such as from nozzle chevrons, pylon treatment and installation, and local liner treatments (Ref 4, 5). However, these reductions are applied to a current engine technology and this, in turn, impacts the technologies to emphasize. As will be shown in this paper, the engine noise itself will be significantly lower, due to advanced engine design such as very high bypass ratio and BWB shielding, so that these small reduction increments may not manifest themselves in the total noise levels because it is the airframe noise components that become dominant.

Another factor that contributes to the significant differences in the noise assessment results is the use of airframe noise prediction tools. Due to the lack of experimental data and the lack of modeling efforts, airframe noise studies for the BWB configurations have only started in recently (Ref 13). It has been shown in these studies that the basic prediction framework and methodologies for conventional aircraft can be applied to BWB aircraft because most of the prediction methodologies are component-based and physics-based, dependent of the source mechanisms but independent of the aircraft types. However, it is also clear that the prediction tools need to be updated and extended to account for the unique features of the BWB design.

\section{BWB Configuration}

The baseline configuration of the BWB design results from a comprehensive design study, (Ref 3), following the best practices in aircraft design as well as incorporating potential technologies that are likely to mature in the next decade, namely, in the timeframe of NASA's N+2 definitions. This allows the design to be practically feasible, to meet various mission requirements, and to achieve a good balance between various factors such as fuel savings and aerodynamic performance. The configuration is a BWB design with two turbofan engines mounted on the upper surface of the airframe structure, as illustrated in Figure 1. The airplane has a medium capacity, long-range mission similar to the Boeing 767 or 787 models. The design specific mission requirements are documented in Ref 3, with the main characteristics of the aircraft summarized in Table 1. In addition to the specific mission requirements, the design meets the Federal Aviation Authority (FAA) FAR Part 25 regulations and other conventional requirements that comprise the Aircraft Level Design Criteria (ALDC). In this section, the design details that are relevant to acoustic analysis are briefly described. 
The airframe design consists of three adjacent payload cabins above a single cargo bay, forming the center body of the BWB airplane. This center body is wrapped with a large, swept wing form, from which, approximately conventional wings extend to form a single, large wing with an extended center body chord. Two outwardly canted vertical stabilizers are mounted on the aft, outboard corners of the center body with two turbofan engines mounted in between. Conventional tricycle landing gears deploy from the lower center body, with the nose gear at the centerline and the main gears at the junction between the center body and the outer wings. The aerodynamic features of the design include a smoothly blended wing-body planform with varying wing chord length along the wing span. The wing cross-section airfoil camber and twist also vary along the span to provide an approximately elliptical lift distribution despite the wide chord variations. The large chord length at the center body results in low section lift coefficients, permitting greater thickness-to-chord ratios despite the Mach 0.85 cruise speed. The low center body section lift coefficients also permit reduced aft camber, providing pitch trim with the elevons faired at the design center of gravity. This design, however, has a disadvantage in acoustics; it significantly reduces the circulatory flow under the airframe so that the local velocity at the main landing gear locations is almost the same as that of the free stream velocity. In contrast, for a conventional aircraft design, the local velocity at the main landing gear location is only about 80 percent of the free stream value. This results in a difference in noise levels of about $6 \mathrm{~dB}$ (Ref 16-18) with the BWB main landing gear component noise being higher.

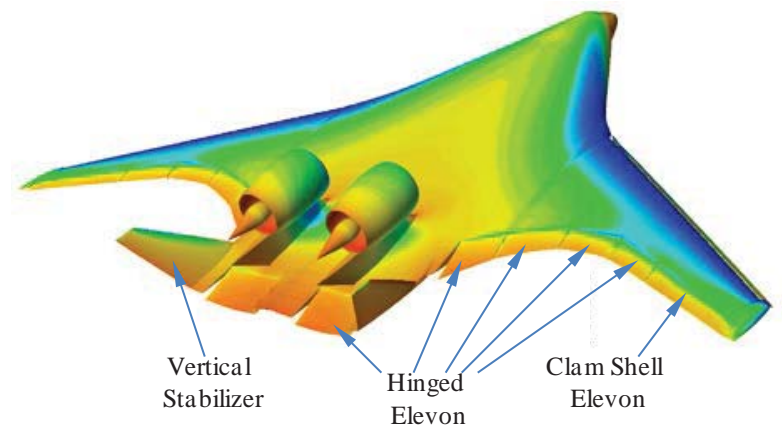

Figure 1 BWB configuration with turbofan engine propulsion, with colors indicating Mach number from low (blue) to high (red).

Table 1 Airplane Mission Requirements

\begin{tabular}{|l|c|c|}
\hline \multicolumn{1}{|c|}{ Parameter } & Unit & Value \\
\hline Number of Passengers & - & 224 \\
\hline Design Payload & $\mathrm{lb}$ & 50000 \\
\hline Maximum Payload & $\mathrm{lb}$ & 90000 \\
\hline Range with Design Payload & $\mathrm{nm}$ & 8000 \\
\hline Maximum Takeoff Weight & $\mathrm{lb}$ & 412199 \\
\hline Cruise Mach Number & - & 0.85 \\
\hline Wing Span & $\mathrm{ft}$ & 213.3 \\
\hline Reference Wing Area & $\mathrm{ft}{ }^{2}$ & 8048 \\
\hline Wing Aspect Ratio & - & 5.62 \\
\hline Reference Thrust & $\mathrm{lb}$ & 92000 \\
\hline Number of Engines & - & 2 \\
\hline Engine Diameter D & in & 121 \\
\hline Engine Position to BWB Trailing Edge & $\mathrm{D}$ & 0.94 \\
\hline
\end{tabular}


As is well-known, the BWB design can provide sufficient lift at landing and takeoff conditions so that flaps are not needed, which is an acoustic advantage because flap side edges are known to be a major airframe noise source on conventional aircraft designs (Ref 19-21). The BWB design has a system of trailing edge elevons and vertical stabilizers for flight control, as illustrated in Figure 1. Pitch control is provided by three simply hinged elevons at the trailing edge of the center body and two similar ones outboard on each side. There is also the potential to use symmetrical deflection of the vertical stabilizers to augment pitch control. Roll control is provided by deflection of the six trailing edge elevons on each outboard wing. The two inboard elevon surfaces are also used for pitch control. Deflection allocation of the six trailing edge devices is varied with airspeed to account for aero-elastic effects. Yaw control is provided by the rudders on the two vertical stabilizers. When additional yaw control power is needed, the rudders are augmented by the outboard two elevons on the wing, which can split into upper and lower portions, either deflecting together to act as an aileron or opening up apart to form a split trailing edge spoiler, providing drag control.

The BWB airframe has 12 sealed variable camber Krueger slats, symmetrically designed about the airframe centerline with 6 on each side. The dimensions of the slats are comparable to conventional designs, but their sweep angles are larger, due to the shape of the BWB platform. The sealed hinged Krueger slats are also considered as an advanced noise reduction design. For conventional slotted slats, the noise comes mainly from two mechanisms, the cove region flow separation and the unsteady flow rushing through the gap between the slat trailing edge and the main wing (Ref 14-16, 19, 22-23). The use of hinged Krueger slats reduces the cove region flow separation and eliminates the gap flow, and hence, this reduces the noise associated with slats.
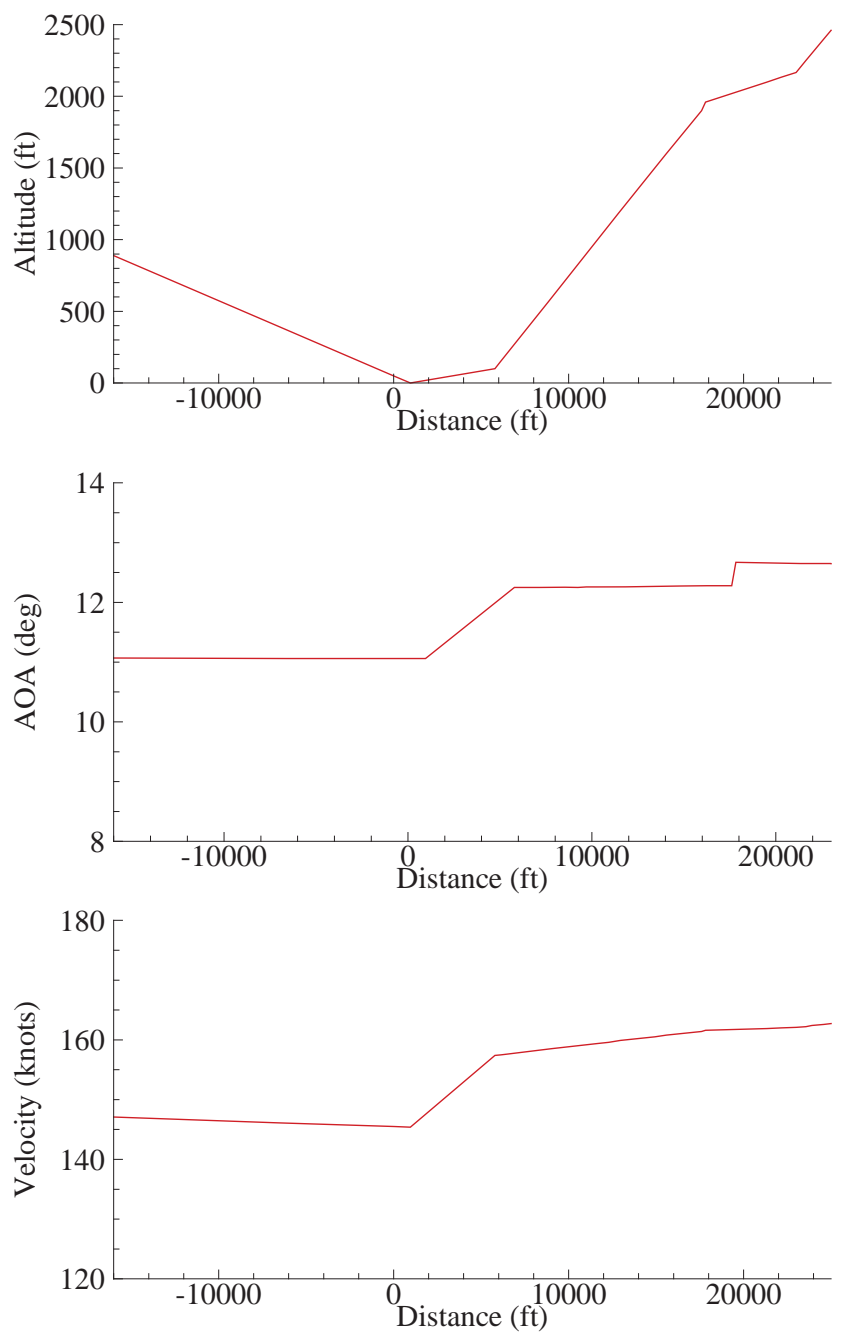

Figure 2 Flight profiles for the BWB aircraft acoustic analysis: flight path (upper), flight velocity (middle) and flight angle of attack (bottom). 
The landing gears are arranged in a tricycle configuration with a nose gear at the airframe centerline and two main gears at the junctions between the BWB center body and the outer wing. The nose gear has two wheels and the main gears have six-wheel trucks in three rows of two wheels each, similar to the main landing gears of the Boeing 777 aircraft. This six-wheel arrangement results in a narrower gear width, enabling the stowed gear to fit in the same depth as the lower deck cargo, compared with a four-wheel truck that requires increased depth, adversely affecting either center body thickness-to-chord ratio or center body chord length.

In aircraft system noise assessment, flight operational conditions play an important role, because the flight parameters such as the flight Mach number and the aircraft angle of attack determine the noise source levels and the flight path determines the distance of the noise propagation, and hence, the amplitude of the noise received at the measurement locations. Similar to aircraft design, flight procedures must also follow practical requirements, set by regulatory rules for safety and/or by airport authorities for operational efficiency. For example, current airport practice requires an aircraft to approach for landing at 3 degrees of flight path. Following rules such as this, the flight profile for the configuration is designed and illustrated in Figure 2 for all three conditions of aircraft noise certification, with the upper diagram plotting the flight altitude as a function and the touchdown distance, the middle diagram plotting the flight velocity and the bottom diagram plotting the flight angle of attack. The flight conditions are also summarized in Table 2.

Table 2 Flight Parameters at Noise Certification Conditions

\begin{tabular}{|c|c|c|c|}
\hline & Approach & Cutback & Sideline \\
\hline Altitude (ft) & 400 & 2099 & 1000 \\
\hline Speed (knot) & 146.1 & 161.9 & 159.4 \\
\hline AOA (deg) & 11.06 & 12.65 & 12.26 \\
\hline Thrust (lb) & 3087 & 46590 & 95064 \\
\hline
\end{tabular}

\section{Advanced Technologies}

To harvest the benefits of technology developments and advances in aircraft design and noise reduction, the BWB configuration includes a suite of technologies that are in active development and are projected to mature and enter service in the next 10 to 15 years. These technologies are described in Ref 3, together with detailed maturation plans, some of which are summarized in Table 3. Of particular interest is the set of technologies that directly impact noise reduction, which can be categorized into three groups; engine noise source level reduction, engine noise shielding and airframe noise reduction. For the engine noise, the source level reduction is always closely related to advances in design technologies that are driven by propulsion efficiency. This is reflected here by the utilization of ultra high bypass ratio engines that meet the fuel savings goal of the mission requirements in the design (Ref 3). This engine architecture also significantly lowers the engine noise, especially the jet noise that is the dominant engine noise component for turbofan engines currently in service. As will be shown in a later section, the jet noise for this advanced ultra high bypass ratio engine design is only a minor contributor to the total engine noise. Source noise level reduction is further helped by the use of advanced acoustic liner inside the inlet and bypass ducts and nozzle of the engine.

The noise shielding technology is a result of the engine installation above the BWB airframe. While this is intuitively obvious, it is interesting to note that BWB designs in the early days (e.g. Ref 1) usually had the engines at or downstream of the airframe trailing edge, which minimizes the aerodynamic installation penalty, but obviously, only provides a shielding effect for engine forward radiated noise. The concept of installing the engines upstream of the trailing edge is mainly for the objective of including a noise reduction from shielding aft-radiated engine noise. For maximum shielding effect, the engines should be as far away from the edges of the airframe as possible, ideally at the center of the BWB platform. This is, however, not a viable option. A critical consideration for BWB configurations with upper surface mounted engines is the interference of the engines with the high speed flows at cruise conditions. Another is the weight balance of the aircraft due to the engines and their supporting structures. These factors dictate that the design has to support the mission requirements. In the design study reported in Ref 3 , it is shown that the engines cannot be placed more than one rotor diameter upstream of the trailing edge, in order to 
avoid severe interference with the high speed flows at cruise. In fact, an engine location of about three quarters of the rotor diameter upstream of the trailing edge would pose much less challenges for the aero-propulsion integration. For the configuration studied here, the design puts the engines at 94 percent of a fan diameter upstream of the BWB trailing edge, which is already pushing the propulsion-aerodynamic integration to the design envelope, in order to maximize the acoustic benefit. The use of vertical stabilizers is also often considered as a noise shielding technology, because they are intuitively considered to be able to block noise in the sideline or horizontal direction. While the limited data available has only shown a marginal acoustic benefit of the vertical tails (with a turbofan engine noise source), their added weight and the cost of aerodynamic performance has been a concern. It has been estimated that up to 3 percent of fuel cost would be needed to have the vertical tails. In that case, it would become really questionable whether the fuel cost is worth the potential acoustic benefit. However, for the configuration studied here, the vertical stabilizers are designed for yaw control, and their acoustic benefits, if any, would be a byproduct of their main functionality.

Table 3 Advanced Technologies Incorporated in the BWB Design

\begin{tabular}{|c|c|}
\hline High Speed Aerodynamics & $\begin{array}{ll}\text { - } & \text { Hybrid Laminar Flow Control } \\
\text { - } & \text { Riblets for Drag Reduction } \\
\text { - } & \text { Raked Wing Tip for Load Alleviation }\end{array}$ \\
\hline Low Speed Aerodynamics & $\begin{array}{ll}\text { - } & \text { Elevon for Flight Stability } \\
\text { - } & \text { Vertical Stabilizer } \\
\text { - } & \text { Hinged Krueger Slat }\end{array}$ \\
\hline Propulsion & $\begin{array}{l}\text { - Ultra High Bypass Ratio Turbofan } \\
\text { - Advanced Inlet Duct Liner } \\
\text { - Advanced Nozzle Liner } \\
\text { - High Temperature Liner }\end{array}$ \\
\hline Structure & $\begin{array}{l}\text { - Composite Fuselage } \\
\text { - Composite Wing } \\
\text { - Composite Empennage }\end{array}$ \\
\hline Acoustics & $\begin{array}{l}\text { - Shielding by BWB Body and Verticals } \\
\text { - Sealed Krueger Slat Gap } \\
\text { - Krueger Slat Cove Filler } \\
\text { - Landing Gear Acoustic Treatment }\end{array}$ \\
\hline
\end{tabular}

For airframe noise, the component noise reduction technologies are mainly for the two major components, the leading edge slats and the landing gears. In the past two decades, there has been extensive research in developing noise reduction technologies for airframe noise components, including concepts such as cove filler and sealed gap for slats (Ref 23-25), and fairings of various kinds for landing gears (Ref 26-28). While none of the concepts has made its way to production aircraft so far, it does not necessarily mean that they will not eventually be viable for practical applications. There are certainly obstacles that have prolonged the transition of these concepts to reality, including the added weight to the aircraft, the cost of implementation and maintenance, and the lack of robustness in noise reduction. Some of these can be expected to be resolved in the next decade. For the BWB configuration considered here, noise reduction credit is taken for the sealed gap and less flow separation in the cove region for slat noise from a slat cove filler, which would likely mature in the form of hinged Krueger slats without gaps. Technologies for reducing landing gear noise are also expected to mature in the next 10 to 15 years, and thus, credit is taken in the noise assessment. The technologies may be in the form of local fairing or redesign of the gear parts, both of which have been actively researched in recent years.

\section{Acoustic Analysis Methodology}

While there are commonly used and validated tools for system noise assessment of conventional aircraft configurations, such as the NASA Aircraft Noise Prediction Program (ANOPP) code and the Boeing in-house tool Modular Component Prediction (MCP), acoustic tools for advanced aircraft configurations such as BWB are still in the development stage. Predictions of engine noise for ultra high bypass ratio engines currently rely heavily on very 
limited data with strong empirical nature. The empirical engine noise tools are currently stand-alone and are not incorporated in system noise assessment tools. For engine noise shielding by the airframe structures, though much effort has been made to develop prediction tools in recent years, these tools are largely still in development. Some of these methods are still to be validated and others are limited by their heavy computational resource requirements. Thus, noise shielding for full configuration aircraft can only be dealt with on the empirical basis by utilizing wind tunnel test data, which is also a stand-alone process as part of the system noise prediction tool package.

Thus, it is of interest to describe the process used in the study for system noise analysis, which is a combination of empirical prediction, component modeling and local feature numerical computation. The process is illustrated in Figure 3, consisting of the following elements to be described. The acoustic analysis process starts with the design specifications, including the design of the airframe structure, engine type and power setting, and flight profiles. The design specifications are the basis for the noise component source level analysis for both the propulsion system and the airframe structure, and the flight profiles determine the operation conditions at the noise certification points. From the aircraft design, propulsion system definitions are used to establish the engine noise source levels for all major engine noise components. The component source levels also include those of the airframe structures, namely, the landing gears, the leading edge slats, and the trailing edge elevons. The component noise source levels are for individual, isolated components, which need to be assembled under the constraints of the particular aircraft configuration to take into account of the inter-component interactions and propulsion airframe aeroacoustic interactions including shielding. This is a major feature of the BWB configuration where the engine noise may be significantly shielded by the airframe structure, effectively reducing the effects of source levels on the far field radiation. Far field noise can also be significantly affected by local flow changes, which are configuration dependent, such as the landing gear locations. The far field noise from all the components is assembled into the total aircraft noise on the energy basis, meaning that the acoustic energies from all the components are summed together incoherently without considering the potential acoustic interactions between the components in the far field. The far field total noise levels are then used to compute the standard noise metrics, such as the Tone Corrected Perceived Noise Level (PNLT) and the Effective Perceived Noise Level (EPNL).

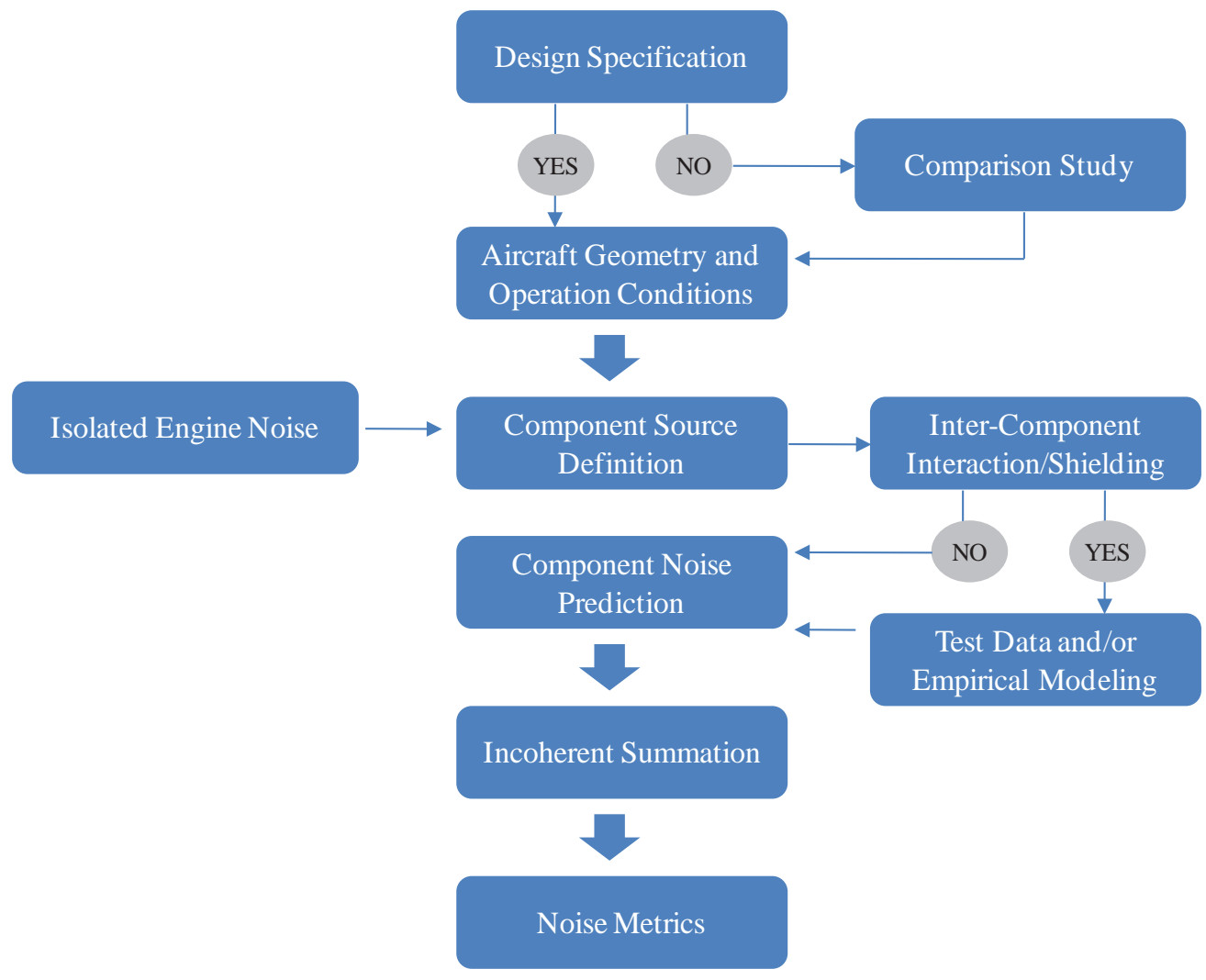

Figure 3 Illustration of acoustic analysis process.

In the acoustic analysis procedure described above, the predictions of the airframe noise components, namely, the leading edge slats, the landing gears and the trailing edge elevons, are based on methodologies developed for 
airframe noise components of conventional aircraft (Ref 14-17, 29). These prediction models can be applied here for the BWB design because the basic elements, such as the spectral features, the Mach number dependence, and the far field directivity of the radiated noise, are based on the fundamental theory of aerodynamic sound generation that captures the flow physics. The predictions are all component-based, with the noise prediction as a function of the local features of the individual components, rather than the overall design of the aircraft. The validation and calibration of the prediction models are also done for the individual components, and are not anchored on any particular aircraft type. This allows the models to have wide and robust applications. The BWB aircraft configuration, however, does have features different from conventional designs, an example being the larger angle of attack at both takeoff and landing configurations, typically above 10 degrees, which is not within the operational range of conventional aircraft, of about 4 to 7 degrees. Thus, slat noise database for conventional aircraft usually does not extend to angles of attack much higher than 7 degrees, and the prediction of BWB slat noise needs to be validated and calibrated for large angles of attack (Ref 13).

Another feature of the BWB design that is different from conventional aircraft is the locations of the main landing gears, which affect the noise because the local flow velocity depends on the local geometry. For conventional aircraft, the main landing gears are located in low speed flows under the lifting wings so that the locations are acoustically advantageous (Ref 17,18 ). In comparison, the BWB main landing gears are in relatively high speed flows without taking advantage of the circulatory flow around the wings, because they are located at the junction between the BWB center body and its outer wings where the local section lift coefficient is low. For landing gear noise prediction, the sound generation mechanisms are all modeled with the incoming flow velocity as an input parameter. The landing gear noise model is readily applicable, provided that the local flow velocity is supplied. This is done by using a Computational Fluid Dynamics (CFD) method to calculate the mean flow for the BWB configuration, from which the local flow velocities are extracted for the noise prediction. An example of the computed local Mach number distributions at the landing gear locations is given in Figure 4 for the case of a mean flow Mach number of 0.2 and an angle of attack of 12 degrees.

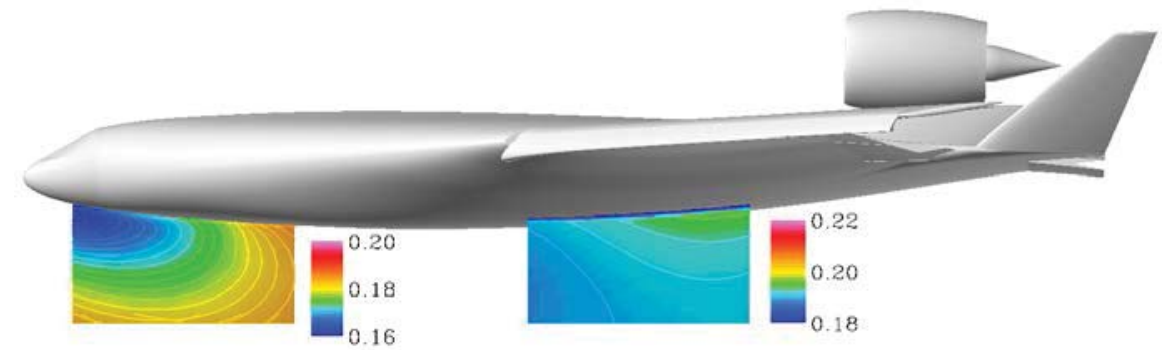

Figure 4 Illustration of Mach number distribution at landing gear locations.

\section{Engine Noise Shielding}

Noise shielding prediction for full configuration aircraft at realistic conditions and frequencies is not currently available. In the past few years, attempts have been made in developing such prediction tools, but the tools either are too time-consuming to be realistically feasible, or are not validated enough to be reliable. Thus, the effects of the BWB shielding on the engine noise are extracted from a database and used directly in the system noise assessment. The model scale propulsion airframe aeroacoustics (PAA) effects wind tunnel test in the Boeing Low Speed Aeroacoustic Facility (LSAF) is reported in Ref 30 and has been used in a similar noise assessment of Ref 4 . The test setup is illustrated in Figure 5, showing the LSAF test section, the BWB airframe platform and the jet nozzle. This is a large database covering parametric variations in flow conditions, BWB airframe design features, engine power settings, engine-airframe integration configurations, and noise reduction concepts, with measurements on the aircraft, in the near field flow, and in the far field. The processing and analysis of the database is beyond the scope of the work discussed here. 


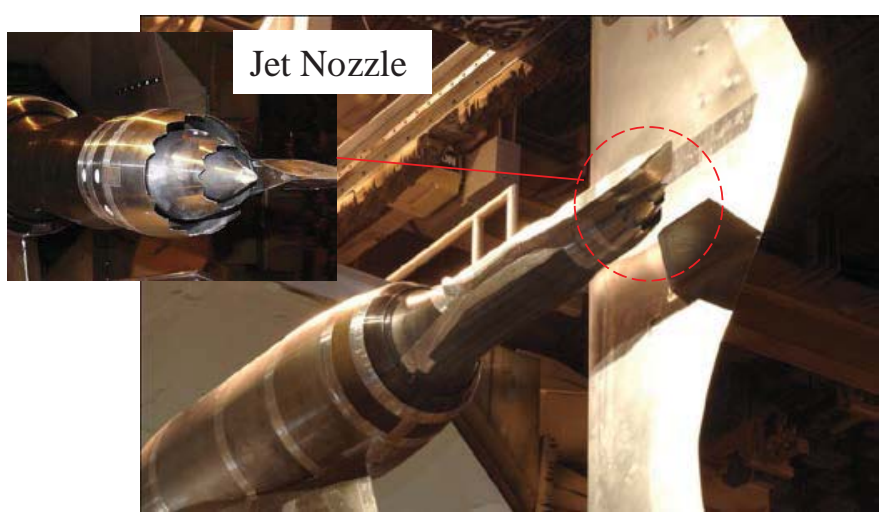

Figure 5 Test setup for the BWB model with jet nozzle installed in the test section of LSAF.

Engine noise shielding is usually achieved when the observation location is in the shielded region of the sources. This can be explained by the shielding angle, whose importance lies in its dominant role in determining the amount of noise shielding. This is graphically explained in Figure 6, where the source distribution and the shielding body with a trailing edge form three zones below the aircraft. In the zone with complete line of sight, the propagation of the noise from the source to the microphones is unobstructed so that the noise in this zone will not be less than the case without the shielding body. In most cases, the noise will be higher because the trailing edge will generate additional noise. In the partially shielded zone where some of the propagation is blocked and some is not so that the noise levels are usually lower than the unshielded case, but the shielding is usually not significant. In the shielded zone, there is no direct propagation from the sources to the microphones so that the shielding efficiency is high, because the only noise reaching the microphones in this zone is from the diffraction at the trailing edge. The shielding efficiency in this zone increases with increasing frequency and forward angle. The amount of engine noise shielding is determined by the location of the engines, the engine installation angle, and the aircraft angle of attack. For this configuration, the engines have an installation angle of 6 degrees, as illustrated in Figure 6, together with the dimensions of the installation geometry. The latter is critical in the shielding efficiency, because it determines the insonified and the shielded region of noise propagation. It should be pointed out that the engine location in this figure is indicated by the distance between the fan nozzle exit plane and the BWB trailing edge (1.64D), which corresponds to 0.94D if measured from the core nozzle, as listed in Table 1.

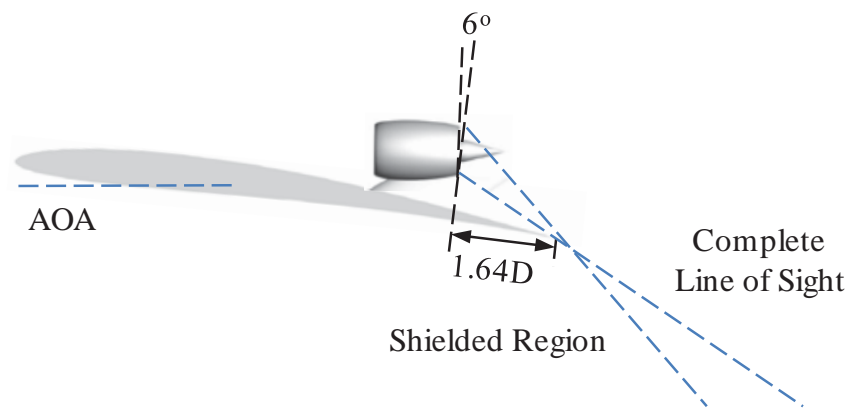

PartialShielding Region

Figure 6 Definition and acoustic features of shielding angles.

The engine noise shielding database from LSAF consists of three types of sources, broadband point source, jet noise source and open rotor tonal noise source. It does not contain duct fan noise sources that dominate the noise from ultra high bypass (UHB) ratio turbofan engines. This makes the use of the shielding data challenging for the tonal fan noise sources and calls for a prioritization of the noise source features that need to be considered, and a combination of different datasets to synthesize the shielding effects for the turbofan engines. The features of the noise sources that may affect the shielding efficiency are listed in Table 4, which clearly shows that none of the datasets can match all the features of the ultra high bypass ratio turbofan engine sources. As a result, the shielding effects can be applied only by matching the most important features, which in order of importance are the shielding angle and geometry, the distributed nature of the sources, the source coherence for the tonal noise, the incoherence 
of broadband noise, and the far field directivity. Based on these, the turbofan tones will use the open rotor database, the core noise will use the broadband point source database, and the jet noise will use the jet noise source database.

\section{Table 4 Features of Engine Noise Sources Compared to Experiment Availability}

\begin{tabular}{|c|c|c|c|}
\hline $\begin{array}{c}\text { UHB Engine } \\
\text { Noise Source }\end{array}$ & $\begin{array}{c}\text { LSAF Open } \\
\text { Rotor Source }\end{array}$ & $\begin{array}{c}\text { LSAF Point } \\
\text { Source }\end{array}$ & $\begin{array}{c}\text { LSAF Jet } \\
\text { Source }\end{array}$ \\
\hline $\begin{array}{c}\text { Spatially } \\
\text { Distributed }\end{array}$ & Yes & No & Yes but Different \\
\hline $\begin{array}{c}\text { Coherent } \\
\text { Tones }\end{array}$ & Yes & No & No \\
\hline $\begin{array}{c}\text { Directional } \\
\text { Radiation }\end{array}$ & Yes but Different & No & Yes but Different \\
\hline $\begin{array}{c}\text { Ducted } \\
\text { Geometry }\end{array}$ & No & No & No \\
\hline $\begin{array}{c}\text { Incoherent } \\
\text { Broadband }\end{array}$ & No & Yes & Yes \\
\hline
\end{tabular}

Thus, the approach to utilize the LSAF test databases for the shielding effects consists of the following steps. First, the appropriate databases are selected. The database can be one of the three source types, or any combinations of them, depending on the characteristics of the engine noise sources. From the databases and the test configurations, the datasets are then found which match the full configurations for which the shielding effects are to be applied. Though the test database contains a large amount of parametric variations, it is not practical to expect exact matches, or even approximate matches for all the parameters. Thus, interpolations are needed when there are no exact matches between the two. The next step is the scaling of the test data, in which the engine power settings in the wind tunnel tests need to be scaled up to match the power settings in full scale configurations and the frequencies need to be scaled down according to the geometry. The amplitudes are not affected by the scaling because the shielding effects are represented by the difference between the isolated engine noise and the shielded engine noise levels; the scaling effects on the absolute amplitudes of the noise levels cancel each other between the two cases. The scaled frequencies are then matched to the full scale engines based on Strouhal number scaling. The shielding effects are then represented and applied by the difference in sound pressure levels in decibels. This can be a straightforward subtraction between the isolated and the installed case in the tests, for overhead locations at approach and cutback conditions because the symmetry of the engines with respect to the overhead microphone locations. The effects of more than one engine are zero on the difference in sound pressure levels. For sideline locations, however, the results from the one-engine tests need to be modified because the engines in the full scale aircraft are not symmetrically installed with respect to the sideline microphones. This non-symmetry affects the shielding because the different lines of sight from the microphones to the engines. 

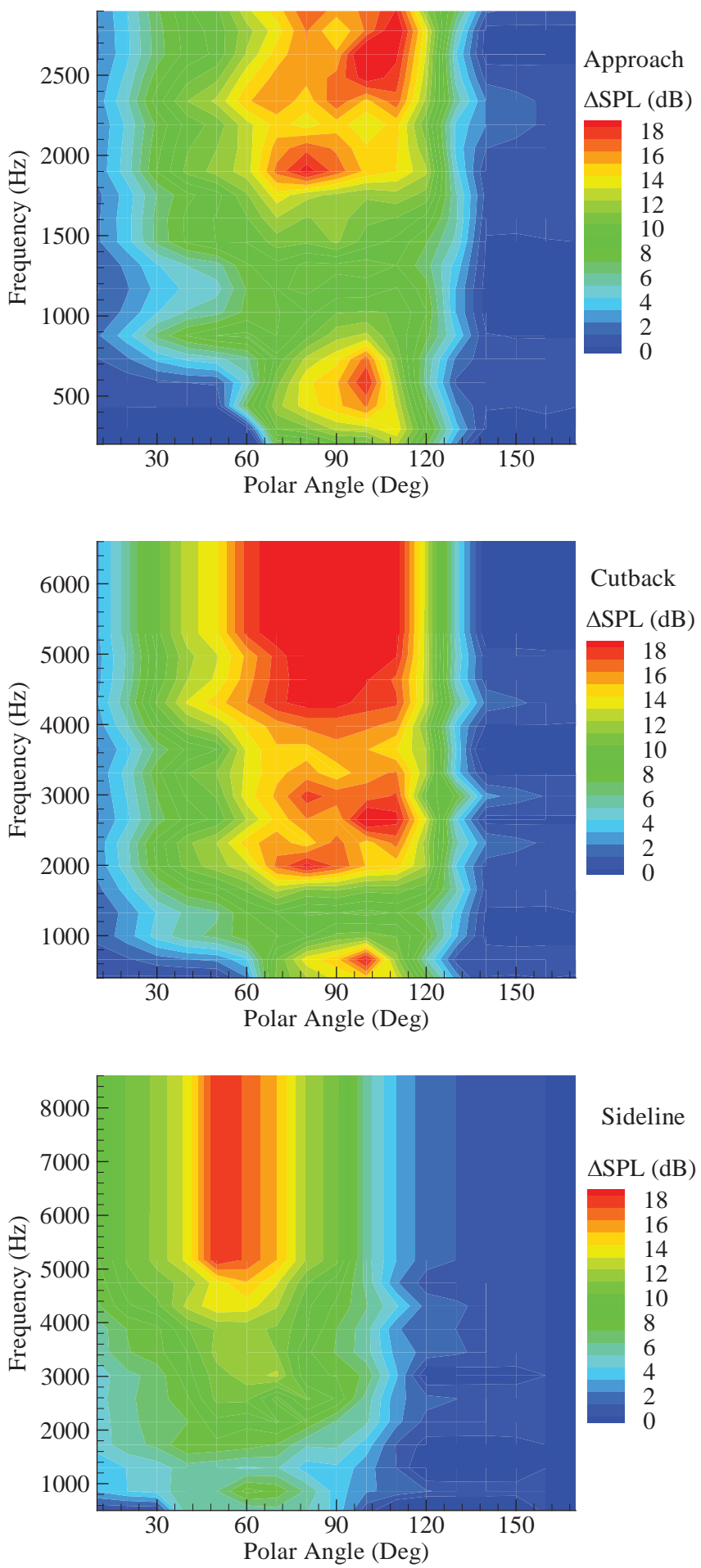

Figure 7 Illustration of fan tone noise shielding effects, respectively for approach (top), cutback (mid) and sideline (bottom) conditions. Full scale frequency.

The shielding effects constructed from the process described above consist of three types, narrowband tonal shielding for inlet and aft fan noise, broadband point source shielding for core noise, and jet noise shielding for the jet component. As an example, the fan noise shielding effects are shown in Figure 7, in which the difference in sound pressure levels are plotted as contours in polar angle and frequency, for the three certification conditions, 
respectively given by the top, middle and bottom diagram. The positive numbers in the plots indicate noise reduction due to shielding. The common features of these plots are the significant shielding in the forward quadrant and the overhead locations, as expected, and the increase in shielding efficiency with frequency, which is also expected. The latter underlines the difficulties associated with shielding low frequency tones, a challenge of ultra high bypass engines. It can also be noted that a large portion of the aft quadrant does not benefit from the shielding effects, indicated by the blue color at large polar angles. For approach and cutback conditions where the measurements are on the flyover path, the unshielded region starts from about 130 degrees, while for the sideline location, this region covers polar angles as low as 100 degrees, slightly over the overhead angle. This illustrates the inefficiency of shielding for engines mounted close to the trailing edge at sideline locations; the three dimensional geometry and emission angles expose the engines to the side microphones for almost all the emission angles.

\section{Results of Acoustic Assessment}

The noise metrics calculated include the tone corrected perceived noise level (PNLT), as a function of observer time, at three noise certification conditions. These are shown in Figure 8, with the top, middle and bottom diagram respectively for the approach, cutback and sideline condition. The corresponding EPNL results are summarized in Table 5, together with the Stage 3 limits and the margins to both Stage 3 and Stage 4.
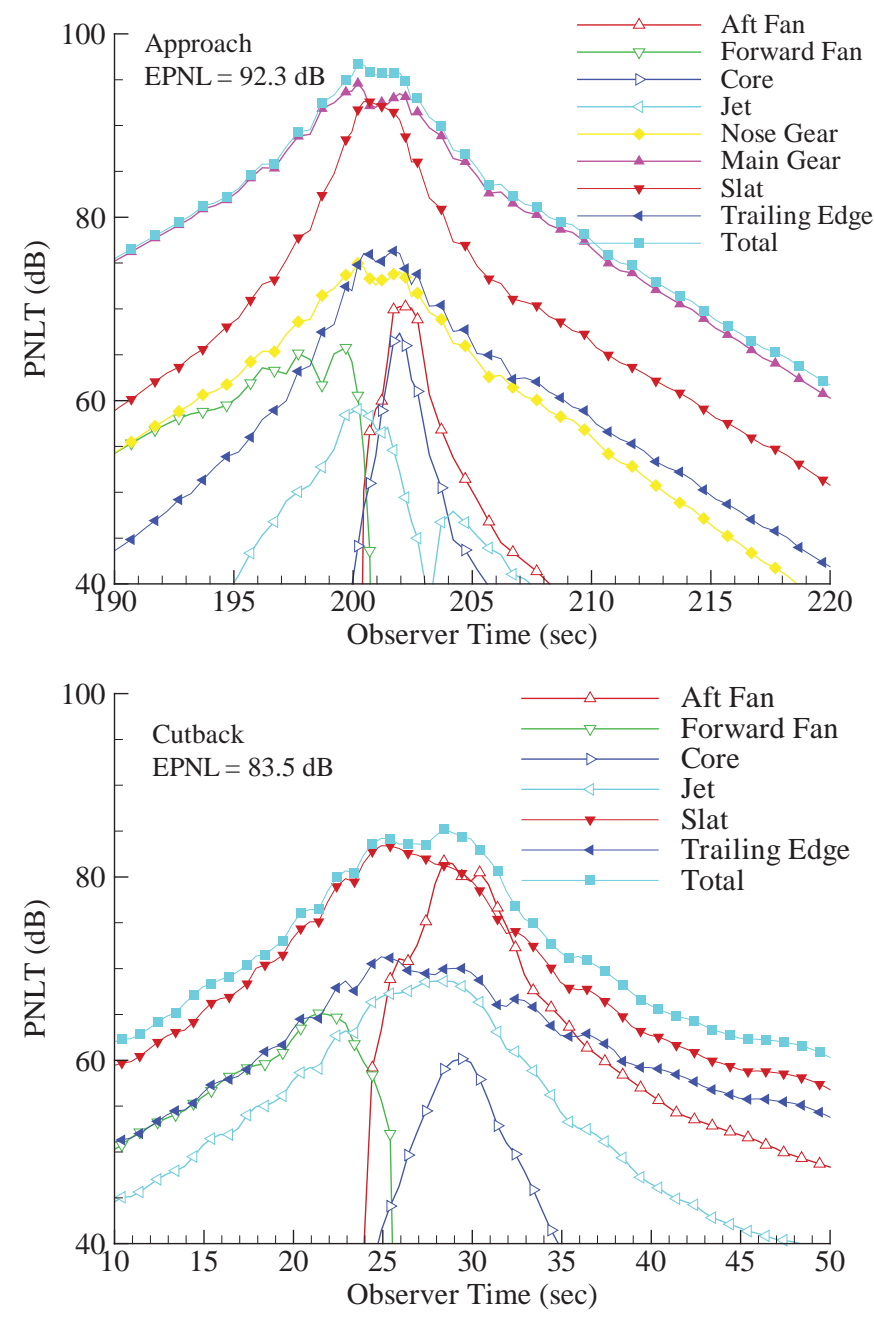


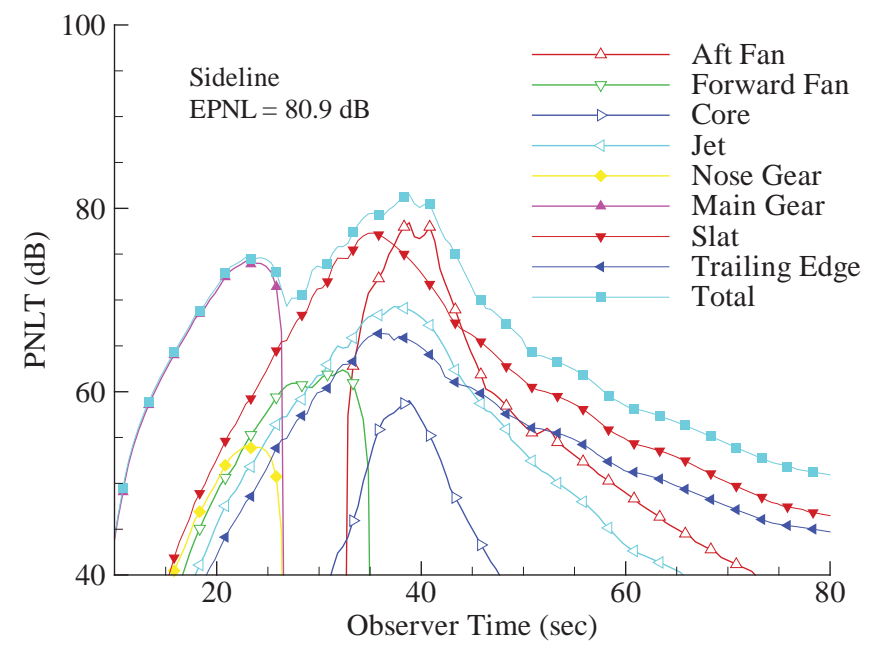

Figure 8 PNLT for the three noise certification conditions of approach (top), cutback (middle), and sideline (bottom).

Table 5 EPNL Results for BWB before Krueger and Landing Gear Noise Reduction

\begin{tabular}{|l|c|c|c|c|}
\hline & Approach & Cutback & Sideline & CUM \\
\hline Stage 3 Limits (dB) & 103.6 & 96.8 & 100.2 & 300.6 \\
\hline EPNL (dB) & 92.3 & 83.5 & 80.9 & 256.7 \\
\hline Margin to Stage 3 (dB) & 11.3 & 13.3 & 19.3 & 43.9 \\
\hline Margin to Stage 4 (dB) & & & & 33.9 \\
\hline
\end{tabular}

These results reveal the details of the acoustic characteristics of this BWB aircraft design. Clearly, the engine components are not dominant at any of the three operation conditions, even though they still make noticeable contributions at cutback and sideline conditions where the aft fan noise is comparable to the slat noise. This is due to both the low levels of the engine noise source amplitudes and the shielding by the BWB airframe. The engine noise reduction by the two effects is so efficient that the approach noise is dominated by the main landing gear and slat, as clearly shown in the top diagram of Figure 8 . The main landing gear noise is very high because of two reasons. First, is that the six-wheel design is assumed to be similar to the main landing gear of the Boeing 777 aircraft. Second, the large number of wheels in the gear assembly and the associated break system for this design are known to be very noisy. The second reason for the high main gear noise is the location of the main landing gear at the junction between the BWB center body and the outer wings. These are regions with high local flow velocity, comparable to the aircraft flight velocity compared with conventional designs for which the local velocity is about $80 \%$ of the flight velocity.

At this stage of the configuration of the BWB, the airframe components are a major source of the noise. For this reason, additional noise reduction is most effectively achieved with the projection of the impact of noise reduction technologies for the Krueger slat and the main landing gear as described in Section III. A total of $3 \mathrm{~dB}$ of reduction is projected across all frequencies for the Krueger slat component for the configuration including a sealed gap and the slat cove filler. For the main landing gear a projected $5 \mathrm{~dB}$ of noise reduction is possible for the landing gear acoustic treatment listed in Section III including redesign and fairings. While there has been little direct research on Krueger noise reduction, $3 \mathrm{~dB}$ is similar to that assumed in recent NASA noise assessments for a conventional slat. For the landing gear, $5 \mathrm{~dB}$ is an aggressive amount of noise reduction but again, it is similar to that assumed in recent NASA noise assessments (Ref 4, 5). 
With the addition of these ambitious levels of noise reduction technologies to these two airframe components, the BWB system level noise is assessed at $41.6 \mathrm{~dB}$ cumulative to Stage 4, a level that essentially meets the NASA $\mathrm{N}+2$ noise goal.

\section{Comparison with Prior NASA HWB Study}

In a study to demonstrate the acoustic potential of the integration of airframes and propulsion systems, NASA has shown that for a particular configuration of a Hybrid Wing Body (HWB) with turbofan engines, the cumulative noise reduction can reach $42.9 \mathrm{~dB}$ in reference to Stage 4 (Ref 4-5) and (more recently at $43.4 \mathrm{~dB}$ updated using current versions of the ANOPP software), compared with the $41.6 \mathrm{~dB}$ shown in this paper. The two configurations have many differing aspects, from the airframe design, to the engine type, to the flight profile, so that detailed comparisons are complicated and yet provide insight into the progression of noise assessment for unconventional aircraft as well as insight into the technology development challenges for an aircraft to reach the NASA $42 \mathrm{~dB}$ noise goal. The NASA HWB assessment originally began formulation in 2003 and was first published in 2009 and then updated in 2010 and 2012. The present study of the AVC BWB was performed in 2011. The framework of the two studies is summarized in Table 6.

Table 6 System Noise Assessment Framework Comparison

\begin{tabular}{|c|c|c|}
\hline & AVC BWB & NASA HWB \\
\hline Overall purpose of study & $\begin{array}{l}\text { Noise assessment of best } 2025 \\
\text { aircraft design to meet NASA } \\
\text { goals simultaneously }\end{array}$ & $\begin{array}{l}\text { Define noise reduction strategy to } \\
\text { achieve } 42 \mathrm{~dB} \text { goal using data for } \\
\text { the key technologies and shielding } \\
\text { effects } \\
\text { Develop understanding of the } \\
\text { acoustic impact of major design } \\
\text { parameters }\end{array}$ \\
\hline $\begin{array}{l}\text { System level metrics for } \\
\text { aircraft design }\end{array}$ & $\begin{array}{l}\text { NASA N+2 noise, fuel burn } \\
\text { and emissions goals }\end{array}$ & Focus on NASA $\mathrm{N}+2$ noise goal \\
\hline Date of initial study & 2011 & 2009 \\
\hline Engine & $\begin{array}{l}2025 \text { very high bypass ratio } \\
\text { with engine noise source } \\
\text { breakdown provided by } \\
\text { manufacturer }\end{array}$ & $\begin{array}{l}\text { NASA model of the GE-90 like engine } \\
\text { used for: } \\
\text { - Confidence in engine source } \\
\text { breakdown, } \\
\text { - Confidence in shielding prediction }\end{array}$ \\
\hline Airframe & Boeing BWB for 2025 & NASA model of HWB \\
\hline $\begin{array}{l}\text { Noise reduction technology } \\
\text { approaches }\end{array}$ & $\begin{array}{l}\text { - } \quad \text { Airframe components } \\
\text { - Advanced acoustic duct } \\
\text { liner }\end{array}$ & $\begin{array}{l}\text { - } \\
\text { - } \quad \text { Low apprame components } \\
\text { - Jet noise reduction and shielding } \\
\text { effectiveness } \\
\text { - Additional aft shielding area with } \\
\text { engine placement } \\
\text { Advanced acoustic liner } \\
\text { applications }\end{array}$ \\
\hline
\end{tabular}

While both studies are assessing noise relative to the $\mathrm{N}+2$ goal, they had frameworks dictated by different purposes and influenced by the different timelines of each study. The earlier timeline of the NASA study meant that the purpose of this study was focused on determining a technical strategy (including identification of the noise benefits of enabling technologies) to reach the noise goal with the use of the only available high quality data for shielding effects, the LSAF PAA data set of Ref 30. In part due to the earlier timeframe and in part due to the 
importance of access to accurate engine source noise breakdown, the NASA study was setup to use a GE90-like engine. (Historically engine noise breakdown is protected information by engine and aircraft manufacturers. Through years of assimilating GE90-like engine information (design, performance and noise data), a representative model of the engine cycles required for accurate noise source prediction was created Ref 4.)

The AVC BWB study was begun at a later time and was setup specifically to assess, with the best available BWB vehicle designed for the noise, fuel burn and emission goals simultaneously. For this reason, the AVC BWB employed the engine with the best technology for the 2025 timeframe, a much higher bypass ratio Pratt \& Whitney Geared Turbofan (GTF) engine. It should be noted that the engine design, performance and noise data for this GTF is protected information and not readily available for use by NASA.

For isolated engines, the UHB engines have lower total engine noise levels, mostly because of the low jet noise associated with ultra high bypass ratio design, making its noise more dominated by tones. Therefore, both due to overall noise levels as well as engine source changes, the choice of engine determines a number of other parameters. In order to achieve the $42 \mathrm{~dB}$ goal, the NASA technical strategy deployed a more aggressive set of parameters and technologies.

Table 7 provides specifications of the key design parameters and technologies that were included in both studies. In the aft radiating direction, the GE90-like engine is dominated mostly by broadband jet noise. While jet noise in general has a more distributed source, and hence, is more difficult to shield, the NASA HWB locates the engines far upstream of the airframe trailing edge to increase the available shielding surface. Furthermore, the NASA HWB uses aggressive PAA chevrons on the jet nozzle that are designed to reduce and relocate the jet peak noise sources closer to the jet exit, further enhancing the airframe shielding effectiveness. On the other hand, the installation of the UHB engines pose different PAA issues since they have low frequency tones that are difficult to shield, a larger diameter engine that exposes more of the exit sources to the far-field microphones, and a closer placement of the engine to the airframe trailing edge all resulting in most of the aft quadrant noise field in direct line of sight of the aft radiated engine sources with only minimal shielding.

Table 7 Technology and Design Variable Comparison

\begin{tabular}{|l|l|l|}
\hline & \multicolumn{1}{|c|}{ AVC BWB } & \multicolumn{1}{c|}{ NASA HWB } \\
\hline Engine & 2025 P\&W GTF BPR 18 & GE90-like BPR 7 \\
\hline $\begin{array}{l}\text { Engine location upstream of } \\
\text { trailing edge }\end{array}$ & $0.94 \mathrm{D}$ & 2D \\
\hline Aircraft approach speed & 144 knots & 115 knots \\
\hline Leading edge device & Krueger slat & Conventional slat \\
\hline Landing gear noise reduction & $\begin{array}{l}\text { Redesign and fairings to } \\
\text { achieve 5 dB component } \\
\text { reduction over baseline }\end{array}$ & $\begin{array}{l}\text { Redesign and fairings to } \\
\text { achieve 5 dB component } \\
\text { reduction over baseline }\end{array}$ \\
\hline Leading edge noise reduction & 3 dB component reduction & None \\
\hline Advanced acoustic duct liner & Inlet and aft duct & Aft duct only \\
\hline Jet noise reduction & None & $\begin{array}{l}\text { Chevrons and crown pylon } \\
\text { for shielding effectiveness }\end{array}$ \\
\hline
\end{tabular}


The low system noise assessed by the NASA HWB is helped by an aggressively low approach speed of 115 knots for the NASA HWB compared to 144 knots for the present study. This gives the NASA HWB a noise advantage of about $6 \mathrm{~dB}$ at approach conditions. While 115 knots is a typical approach speed of smaller regional jet aircraft, for a larger aircraft of the BWB size it is much more of a challenge from an aircraft design and from airport operation requirements. Increasing wing area or advanced flow control lift augmentation are proposed approaches, but these have not been studied nor has the aircraft system level impacts.

The difference in engine installation between the present study and the NASA HWB study is listed as the engine distance to the trailing edge, about one fan diameter for the present study and about two diameters for the NASA HWB. As discussed earlier this distance is critical in determining the shielding effect, and in the present study it is additionally constrained by other requirements, such as aerodynamics and propulsion efficiency in order to simultaneously meet NASA goals for noise and fuel burn. Since the purpose of the NASA study was to define noise reduction approaches to achieve a $42 \mathrm{~dB}$ reduction in noise, the distance was set at the aggressive two diameter location. One of the objectives of that purpose was to explore and provide estimates of the acoustic benefits and to motivate innovative implementations of the approach based on the acoustic benefit. In this case that would be to push the airframe design to accommodate engines placed at two diameters upstream of the trailing edge, if the trade between noise and performance is beneficial. The approach speed is another example, where the NASA HWB study shows the trends by which the noise can be reduced. The present study, with its purpose to assess the best 2025 aircraft design to meet simultaneous goals of noise and fuel burn does not consider this a viable approach at this time due to the practical constraints discussed earlier.

Another factor that significantly contributes to the different assessments is the prediction methodology. Some of the important issues are listed in Table 8. One of the most difficult issues with noise assessments of unconventional aircraft has been the effect of shielding for the different engine components. In this case, both studies used a hybrid prediction method where the same high quality experimental database of Ref 30 for PAA shielding effects is used for the prediction of shielding within the analytical system noise prediction process.

Another area of improvement made by the current study is in the area of the BWB airframe noise prediction, including the landing gear noise and the slat noise, the two dominant components of BWB airframe noise, as listed in Table 8. This is predominantly due to the unavailability of accurate and updated prediction tools at the time of the NASA study. The development of airframe noise prediction tools have largely been focused on conventional aircraft (Ref 14-18). Though these tools are component-based and physics-based so that in principle they are applicable to arbitrary aircraft configurations if used as component prediction. However, they need to be extended and reassembled to account for the unique design and operating features of the BWB aircraft, which is attempted only in recent years (Ref 3,13$)$.

For landing gears, a unique feature is the local flow velocity at the main landing gear location. As illustrated in Figure 4, the local mean flow velocity into the main gear assemblies for the BWB is on the order of 96\% (of freestream) rather than the $80 \%$ for conventional tube-and-wing aircraft. In the NASA study, the mean flow velocity was set at the $80 \%$ value, since it was shown achievable for a tube-and-wing aircraft and deemed a viable noise reduction strategy/technology for HWB aircraft. Since the noise amplitude is proportional to the six power of the flow velocity, the use of a much lower local velocity, $80 \%$ compared to $96 \%$, leads to much lower landing gear noise level (about $5 \mathrm{~dB}$ ) reported for the NASA study than the present study. Again the NASA study reported the acoustic benefit of reduced mean flow velocity on landing gear noise with the objective to provide motivation for noise reduction technology development. The maximum tone-corrected perceived noise levels (PNLT) for the main landing gears at approach conditions was reported to be about $81 \mathrm{~dB}$ in Ref 4 and $68 \mathrm{~dB}$ in Ref 9, while it is shown in Figure 8 of this paper to be about $93 \mathrm{~dB}$. In sum, for the study in Ref 4, the underestimate of $12 \mathrm{~dB}$ landing gear noise partially comes from the lower approach speed assumed in that study and partially results from the failure to account for the effects of high speed flows at the landing gear location for the BWB design. In addition to these, the study in Ref 9 also assumed some very aggressive technologies that are not likely to mature in the next 10 to 15 years, which resulted in the huge underestimate of $25 \mathrm{~dB}$ of landing gear noise. 
Table 8 System Noise Assessment Method Comparison

\begin{tabular}{l|l|l|}
\hline & \multicolumn{1}{c|}{ A VC BWB } & \multicolumn{1}{c|}{ NASA HWB } \\
\hline Shielding effects & $\begin{array}{l}\text { Prediction with LSAF PAA } \\
\text { experimental data }\end{array}$ & $\begin{array}{l}\text { Prediction uses LSAF PAA } \\
\text { experimental data }\end{array}$ \\
\hline Fan noise shielding & $\begin{array}{l}\text { Applies separate broadband } \\
\text { and tone shielding PAA data } \\
\text { to fan noise source } \\
\text { components }\end{array}$ & $\begin{array}{l}\text { Applies only broadband } \\
\text { shielding PAA data to both } \\
\text { broadband and tone fan } \\
\text { components }\end{array}$ \\
\hline $\begin{array}{l}\text { Altitude for sideline point } \\
\text { evaluation }\end{array}$ & \multicolumn{1}{c|}{$1000 \mathrm{ft}$} & \multicolumn{1}{c}{$985 \mathrm{ft}$} \\
\hline $\begin{array}{l}\text { Sideline / Cutback procedure } \\
\text { Calculated in separate } \\
\text { procedures }\end{array}$ & $\begin{array}{l}\text { Calculated in separate } \\
\text { procedures }\end{array}$ \\
\hline $\begin{array}{l}\text { Leading edge component } \\
\text { prediction }\end{array}$ & $\begin{array}{l}\text { Updated prediction method } \\
\text { Local velocity at main landing } \\
\text { gear }\end{array}$ & $\begin{array}{l}\text { Existing ANOPP method } \\
\text { with additional calibration }\end{array}$ \\
\hline
\end{tabular}

Similarly, the slat noise was significantly lower in the NASA study, although a major contributor to the total airframe noise, and much less important for sideline and cutback. In this paper, it is shown in Figure 8 that slat noise is a major contributor to the total BWB aircraft noise for all three noise certification conditions. As acknowledged in Ref 4, the slat noise in that study was estimated with an existing prediction tool for conventional slats, mainly as a placeholder for this noise component, because a functional prediction tool was not ready at that time. In the past few years, the capability of predicting slat noise has advanced significantly, not only for conventional designs but also for BWB configurations and operating conditions (Ref 13-15), with validations showing accurate capturing of the parametric trends in the radiated noise, as well as accurate prediction of the absolute noise levels. This provides reliability for the predictions given in this paper, which can be considered as an update to previously reported BWB slat noise levels.

The component levels and their relative ranking of importance directly determine the total noise levels. If a component level is underestimated which is also the noise floor for the total noise, the effects of noise reduction technologies on the other components will be overestimated. The NASA HWB study seems to be such a case. In that study, the baseline configuration has a cumulative EPNL margin of about $26 \mathrm{~dB}$. The margin is increased to about $43 \mathrm{~dB}$ only after a series of engine noise technologies are applied, including engine installation position, aggressive nozzle chevrons, low noise pylons and liner treatment. All these technologies have been demonstrated in model scale tests to be acoustically beneficial, but the benefits have a large impact on the NASA HWB due to the relatively higher levels of the GE90-like engine compared to the airframe level. Indeed, the NASA study showed that even after the shielding effects are applied, the dominant noise comes from the jet for the sideline and flyover conditions. The landing gear noise reduction applied on the NASA HWB study impacted only the approach EPNL, and even for that condition the impact was minimized since the engine noise components were also of importance, as shown in Figure 9. On the other hand, with the airframe noise properly accounted for and with a much lower engine noise from the UHB on the present study, Figure 8 shows that the airframe noise completely controls the total noise levels at approach conditions and is comparable to aft fan noise at the other conditions. Thus, the airframe noise, and to a lesser degree, the aft fan noise, is holding up the total noise levels. Comparison of these studies is a dramatic demonstration of how different purposes influence the definition of the best noise reduction approaches and how the results from those approaches at the aircraft system level are influenced by the framework and technology level of the aircraft concepts. 


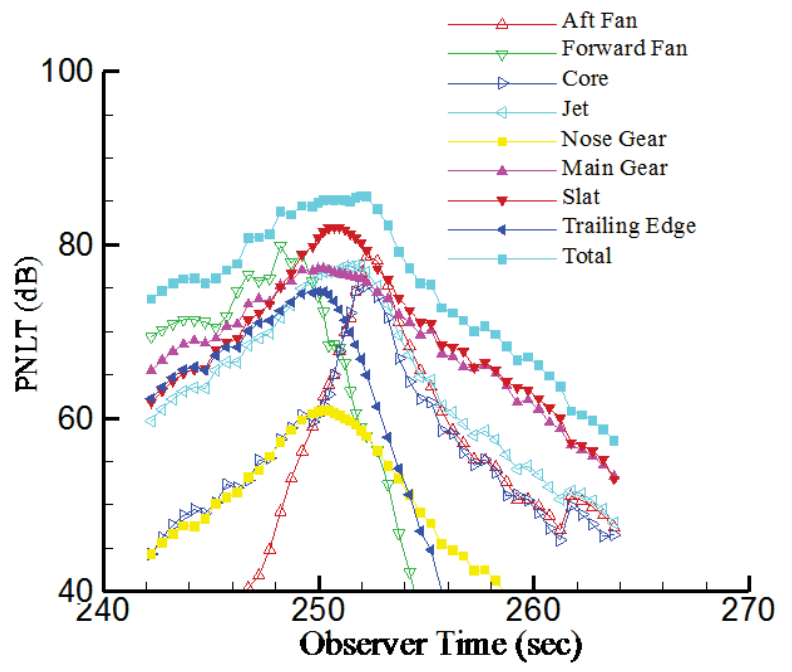

a) Approach, EPNL $=82.8 \mathrm{~dB}$

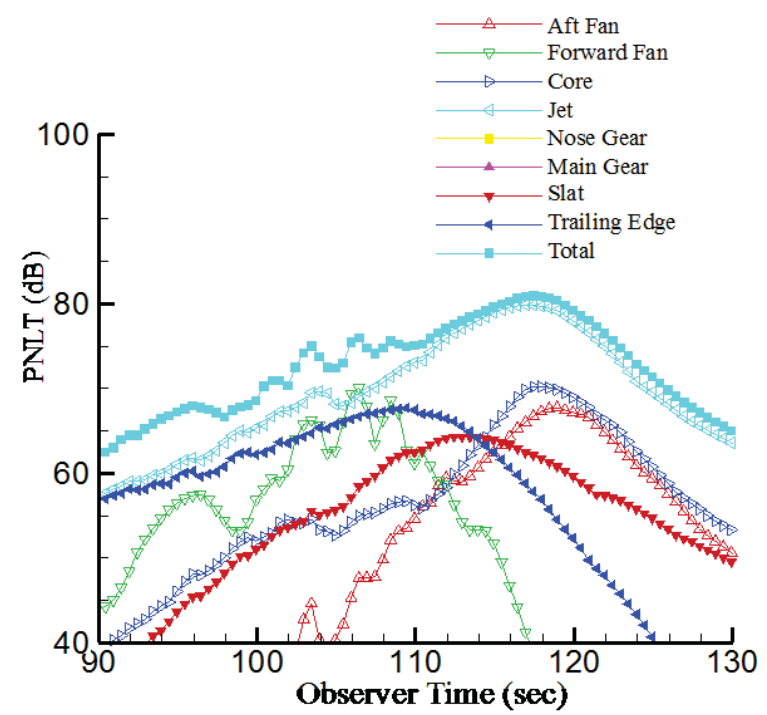

b) Cutback, EPNL $=81.0 \mathrm{~dB}$

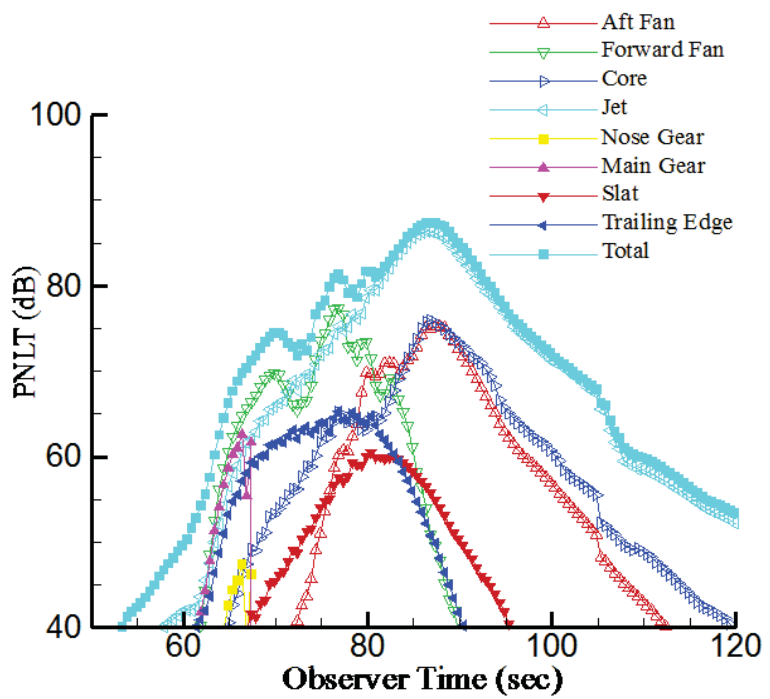

c) Sideline, $\mathrm{EPNL}=\mathbf{8 6 . 9} \mathrm{dB}$

Figure 9 PNLT for three noise certification conditions of the lowest noise configuration (C11) from NASA HWB study, Ref 4. 
The two studies taken together offer considerable understanding of the state-of-the-art in HWB noise assessment as well as identification of key issues/technologies with noise benefits at the aircraft level that offer guidance for future research and development. A summary of the key outcomes of these two studies is shown in Table 9. Together the two studies map the technical approaches necessary for an HWB to reach the NASA N+2 noise goal depending on, in large part, the engine type selected. The use of the shielding data from the LSAF PAA experiment greatly adds to the confidence in both assessments. The present study has also improved greatly on the prediction of the airframe components and highlighted the relative importance of the airframe when advanced very high bypass ratio engines are installed.

Table 9 Key Outcomes of Both Studies

\begin{tabular}{|c|c|c|}
\hline & AVC BWB & NASA HWB \\
\hline Framework & $\begin{array}{l}\text { Rigorous noise assessment for } \\
2025 \text { BWB aircraft with } \\
\text { balanced N+2 goals }\end{array}$ & $\begin{array}{l}\text { First assessment showing } 42 \\
\text { dB with HWB and using } \\
\text { high quality PAA shielding } \\
\text { data } \\
\text { Implemented hybrid } \\
\text { prediction approach for } \\
\text { HWB and first use of } \\
\text { NASA's ANOPP2 } \\
\text { framework }\end{array}$ \\
\hline Overall & $\begin{array}{l}\text { Developed noise reduction } \\
\text { approach to achieve } 42 \mathrm{~dB} \text { goal } \\
\text { with a UHB engine and } \\
\text { meeting fuel burn goal }\end{array}$ & $\begin{array}{l}\text { Defined noise reduction } \\
\text { approach to achieve NASA } \\
\text { noise goal of } 42 \mathrm{~dB} \text { with a BPR } \\
7 \text { engine }\end{array}$ \\
\hline PAA Effects & $\begin{array}{l}\text { - Developed approach to } \\
\text { apply LSAF PAA shielding } \\
\text { data to UHB engine } \\
\text { broadband and tones }\end{array}$ & $\begin{array}{l}\text { Demonstrated impact of } \\
\text { shielding effectiveness } \\
\text { technology }\end{array}$ \\
\hline Airframe & $\begin{array}{l}\text { - First assessment of Krueger } \\
\text { slat on HWB } \\
\text { - Applies proper local flow } \\
\text { velocity for landing gear } \\
\text { - Aggressive landing gear } \\
\text { reduction necessary to reach } \\
\text { goal } \\
\text { Demonstrated importance of } \\
\text { airframe components even at } \\
\text { cutback and sideline }\end{array}$ & $\begin{array}{l}\text { Aggressive landing gear } \\
\text { noise reduction necessary to } \\
\text { reach goal }\end{array}$ \\
\hline Approach Velocity & $\begin{array}{l}\text { Used a conservative approach } \\
\text { velocity }\end{array}$ & $\begin{array}{l}\text { Quantified potential from } \\
\text { approach velocity reduction }\end{array}$ \\
\hline
\end{tabular}

\section{Conclusions}

An analysis has been presented for the system noise assessment of a BWB aircraft design with ultra high bypass ratio engines mounted above the airframe upstream of the trailing edge, a configuration that follows the practical aircraft design principles and incorporates advanced technologies projected to be available in the next 10 to 15 years. With technologies such as advanced engine design, upper surface engine installation, and hinged Krueger slats, the analysis has confirmed the acoustic benefit of such a configuration, with a cumulative EPNL margin of about $34 \mathrm{~dB}$ to Stage 4 . The analysis has also revealed a new ranking order of importance between the noise components, with the airframe noise being the major component, which is drastically different from current conventional aircraft with jet noise as the dominant component. 
While the predicted noise level for this baseline BWB configuration has a comfortable margin to the aircraft noise regulations, the results are significantly different from previously published results. Comparisons have been given in this paper to identify the sources of the differences. It has been shown that these include differences in the purpose of the study, the assumptions of available technologies in the projected timeframe, the locations of the engine installation, the flight profile, and the accuracy of the component prediction such as airframe noise. These directly affect the predicted levels of the components, and hence, the total noise. More importantly for system noise studies, the failure to identify the proper new major noise components results in an error in the noise floor that, in turn, can limit the effectiveness of a noise reduction strategy. Thus, the acoustic benefits of these technologies can be overestimated.

Given the importance of the airframe sources after the engine sources have been reduced by both the high bypass ratio and shielding by the airframe, further reductions in aircraft system noise can be projected with airframe component noise reduction. An additional configuration was considered with the addition of noise reduction technology on the main landing gear and the Krueger slat components. Assuming an ambitious level of noise reduction for each of these two components results in the BWB concept achieving a level of 41.6 EPNLdB cumulative below the Stage 4 requirement.

It should be emphasized that though the design of the BWB aircraft studied here follows the common practice in aircraft design, the configuration does incorporate a series of advanced technologies, both for noise reduction and for other functions. The prediction of a noise margin of 41.6 EPNLdB below Stage 4 relies on the full success maturation of noise reduction technologies in the timeframe of the next 10 to 15 years, recognized as a significant technical challenge. A considerable research and development effort remains necessary for the identified airframe noise reduction technologies.

Considering the current result for an advanced technology BWB capable of 41.6 EPNLdB below Stage 4, a final note of perspective is offered with a comparison to the estimated noise level of a BWB that uses only current day technology. In this case, the isolated engines would be about $7 \mathrm{~dB}$ noisier for the currently available bypass ratio; the engine installation would be between one half to three quarters of a fan diameter from the trailing edge, with about 2 $\mathrm{dB}$ less shielding, this location would allow for feasible propulsion-aerodynamic integration. For the airframe, the slats would be the conventional slotted type without laminar flow control and would result in about $3 \mathrm{~dB}$ more noise. The landing gear noise would be about $3 \mathrm{~dB}$ more without the assumption of successful treatment. These altogether would amount to a noise increase and a cumulative approximate EPNL margin of about $19 \mathrm{~dB}$ to Stage 4. This can be compared with about $15 \mathrm{~dB}$ below Stage 4 for an equivalent conventional aircraft such as the Boeing 787 and the Airbus 380; the $4 \mathrm{~dB}$ or so noise reduction from conventional to BWB design would mainly come from the shielding of forward noise while the other noise components are basically comparable between the two.

\section{Acknowledgments}

The work reported here was sponsored by the NASA Environmentally Responsible Aviation Project under NASA SMAAATAV Contract NNL04AA11B, Task Order NNL10AA71T.

\section{References}

1. Liebeck R. H. "Design of the Blended-Wing-Body Subsonic Transport” AIAA Paper 2002-0002.

2. Nickol C. L. \& McCullers L. "Hybrid Wing Body Configuration System Studies” AIAA Paper 2009-931.

3. Bonet J. T., Schellenger H. G., Rawdon B. K., Elmer K. R., Wakayama S. R., Brown D. \& Guo Y. P., "Environmentally Responsible Aviation (ERA) Project - N+2 Advanced Vehicle Concepts Study and Conceptual Design of Subscale Test Vehicle (STV),” NASA Contract Report 2013-216519, 2013.

4. Thomas R. H., Burley C. L. and Olson E. D. "Hybrid Wing Body Aircraft System Noise Assessment with Propulsion Airframe Aeroacoustic Experiments” International Journal of Aeroacoustics 11, 369-410, 2012.

5. Thomas, R.H. and Burley, C.L., "Progress Toward the N+2 Noise Goal: HWB Propulsion Airframe Aeroacoustics Boeing/NASA Low Speed Aeroacoustics Facility Experiment and System Noise Assessment," presentation to the NASA Fundamental Aeronautics Program Third Annual Meeting, Atlanta, Georgia, September 29-October 1, 2009.

6. Kawai R., et al, “Acoustic Prediction Methodology and Test Validation for an Efficient Low-Noise Hybrid Wing Body Subsonic Transport” NASA Contract Number NNL07AA5C Final Report, February, 2011.

7. Drake, A., "NASA Environmentally Responsible Aviation N+2 Advanced Vehicle Study," presentation at the AIAA Aerospace Sciences Meeting, January 11, 2012, Nashville, Tennessee.

8. Hileman J. I., Spakovszky Z. S., Drela M. \& Sargeant M.A. “Airframe Design for Silent Aircraft” AIAA Paper 2007-0453, 2007. 
9. Manneville, A., Pilczer, D., and Spakovszky, Z., "Preliminary Evaluation of Noise Reduction Approaches for a Functionally Silent Aircraft,” AIAA Journal, Vol. 43, No. 3, pp. 836-840, 2006.

10. Crichton, D. de la Rosa Blanco, E., Law, T., and Hileman, J. "Design and operation for ultra low noise take-off," AIAA Paper 2007-0456, 2007.

11. Hileman, J. I., Reynolds, T. R., de la Rosa Blanco, E., and Law, T., "Development of Approach Procedures for Silent Aircraft,” AIAA Paper 2007-0451, 2007.

12. Lighthill M. J. "On Sound Generated Aerodynamically I. General Theory” Proceedings of the Royal Society of London A211, 564-587, 1952.

13. Guo Y. P., Brusniak L., Czech M. \& Thomas R. H. "Hybrid Wing-Body Aircraft Slat Noise," AIAA Journal, 111, 10.2514/1.J052540, posted online 11 October 2013.

14. Guo Y. P. “Aircraft Slat Noise Modeling and Prediction” AIAA Paper 2010-3837 (2010)

15. Guo Y. P. "Slat Noise Modeling and Prediction” Journal of Sound Vibration. 331, 3567-3586, 2012.

16. Guo Y. P. "A statistical model for landing gear noise prediction” Journal of Sound and Vibration 282, 61-87, 2004.

17. Guo Y. P. “A component-based model for aircraft landing gear noise prediction” Journal of Sound Vibration 312, 801-820, 2008.

18. Guo Y. P. "Effects of Local Flow Variations on Landing Gear Noise Prediction and Analysis" Journal of Aircraft 47, 383-391, 2010.

19. Guo Y. \& Joshi M. "Noise Characteristics of Aircraft High Lift System,” AIAA Journal, 41(7), 1247-1256, 2003.

20. Dobrzynski, W., Nagakura, K. Gehlhar, B. and Buschbaum, A. "Airframe Noise Studies on Wings with Deployed High-Lift System” AIAA Paper 1998-2337, June 1998

21. Brooks T. F. \& Humphreys W. M. Jr. "Flap Edge Aeroacoustic Measurements and Predictions," Journal of Sound and Vibration. 261, 31-74, 2003.

22. Dobrzynski W. \& Pott-Pollenske M. "Slat Noise Source Studies for Farfield Noise Prediction" AIAA Paper 2001-2158, 2001.

23. Mendoza J. M., Brooks T. F. \& Humphery W. M. “Aeroacoustic Measurements of a Wing/Slat Model” AIAA Paper 2002-2604, 2002.

24. Imamura T., Ura H., Yokokawa Y. Enomoto S., YamamotoK. \& Hirai T. "Designing of Slat Cove Filler as a Noise Reduction Devices for Leading-Edge Slat” AIAA Paper 2007-3473.

25. Guo Y. P., “A Discrete Vortex Model for Slat Noise Prediction” AIAA Paper 2001-2157, 2001.

26. Ravetta P. A., Burdisso R. A., Ng W. F., Khorrami M. R. \& Stoker R. W. "Screening of Potential Noise Control Devices at Virginia Tech for QTD II Flight Test” AIAA 2007-3455, 2007.

27. Dobrzynski W., Chow L. C., Smith M., Boillot A., Dereure O. \& Molin N. "Experimental Assessment of Low Noise Landing Gear Component Design” AIAA Paper 2009-3276, 2009.

28. Dobrzynski W., Chow L. C., Guion P. \& Shiells D "Research into Landing Gear Airframe Noise Reduction" AIAA Paper 2002-2409, 2002.

29. Guo Y. P., "On Trailing Edge Noise Modeling and Prediction for Aircraft High Lift Wings" NASA Contract Report NASA Contract NNL07AA03A, 2010.

30. Czech M. J., Thomas R. H. \& Elkoby R. "Propulsion Airframe Aeroacoustic Integration Effects of a Hybrid Wing Body Aircraft Configuration,” International Journal of Aeroacoustics, Vol. 11, Number 3+4, 2012, pp. 335-368. 